\title{
News You Need to Know: Examining the Prioritization of News Content in Print and Online Publications
}

\author{
Jennifer Brannock Cox
}

Department of Communication Arts, Salisbury University, Salisbury, USA

\begin{abstract}
This study examines the prioritization of news in print and online from two sources: traditional newspapers and online-only organizations. A content analysis of four newspapers in print and online and four online-only organizations for one constructed week revealed very few differences in the content these organizations chose to prioritize in the news product. A lack of content diversity could indicate news organizations are not attempting to appeal to print and online readers in different ways. The relative paucity of differences may reflect the relative newness of online-only organizations and of the online medium in general, as well as the tendency of journalists to uphold longstanding journalism routines.
\end{abstract}

Keywords: Journalism; Online journalism; Online-only; Content analysis; Story topics; Prioritization

\section{Introduction}

Writing for the Internet has transformed from an afterthought to a necessity in recent years, forcing newspaper journalists to approach their writing and reporting process in new ways. Online technologies put readers in the driver's seat, with search engines allowing them to customize their news rather than going directly to a print newspaper or website, all but eliminating the gatekeeping journalists who choose the prioritization of content in their print and online products. The availability of online metrics that enable news organizations to track what people are reading have made it nearly impossible for journalists to ignore readers' preferences for particular news topics and story types, potentially influencing journalists' decisions regarding what items will be considered news. Additionally, new competitors to newspapers have cropped up online, providing news content in the same geographic area for a fraction of the operating costs [1].

The theory of the firm posits that the goal of any organization is to obtain profits $[2,3]$. Research indicates print and online readers favor different topics and story types, potentially leading news organizations to prioritize preferred subjects in the news product. Organizations with daily print products must appeal to subscribers to generate profits and guarantee advertisers their messages will be seen regardless of that day's news content [4]. However, organizations that publish primarily online cannot appeal to a steady subscriber base and instead must consistently publish content that will draw readers to click on their websites to generate a profit. This study examines whether news organizations are shifting the ways in which they prioritize news based on reader preferences in an effort to act in their own financial best interests.

A quantitative content analysis was used to analyze one constructed five-day weeks' worth of items $(n=597)$ in the print and online editions of newspaper organizations and the online editions in web-only organizations. Four cities-each containing an organization producing items in print four or more days a week and another producing online content only-were selected for the study. A total of eight organizationsone traditional newspaper and one online-only new organizationwere selected from each city. The top 10 items in each publication in print and online were collected each day to determine what kinds of news each type of organization prioritized. Coders examined the presentation of each item, as well as their news topic, timeliness, and story type. The results provide an empirical assessment of the editorial attributes that differentiate traditional newspapers from their online competitors, as well as those that differentiate the print medium from online. A determination of how news organizations are responding to reader preferences in print and online to determine whether they are working for or against their own best financial interests could be crucial for predicting the staying power of those news organizations in the coming years.

\section{Literature Review}

\section{Prioritizing news}

Looking at what news items are prioritized in newspaper and online-only products can help determine how these organizations hope to attract readers to the news product. Studies have indicated that news items that garner the most attention from readers are often granted more space in print and online [5-7]. News topics and story types may also be emphasized in the news product based on journalistic commitments to serving the public. Topics and values that journalists deem to be important for citizens to function in society are occasionally granted emphasis over more popular stories [8-10].

Organizations define for the audience the importance of some items over others in printed newspapers using generally accepted hierarchical styles. News items that are granted more space on a page, including larger headlines and additional features, such as graphics and photos, signal to readers that those stories should be considered the most important. A study determining how newspaper audiences select news items to read identified article location, headline size, and story length as key factors. Articles located closest to the front of the printed newspaper and those featuring larger-sized headlines than others surrounding them were more likely to be read by news consumers [11]. Printed news stories with photos or graphics accompanying them also

*Corresponding author: Jennifer Brannock Cox, Department of Communication Arts, Salisbury University, 279 Fulton Hall, Salisbury, USA, Tel: 410 677-6512; E-mail: jbcox@salisbury.edu

Received June 05, 2014; Accepted July 23, 2014; Published July 30, 2014

Citation: Cox JB (2014) News You Need to Know: Examining the Prioritization of News Content in Print and Online Publications. J Mass Communicat Journalism 4: 210. doi:10.4172/2165-7912.1000210

Copyright: (c) 2014 Cox JB. This is an open-access article distributed under the terms of the Creative Commons Attribution License, which permits unrestricted use, distribution, and reproduction in any medium, provided the original author and source are credited. 
convey an organization's desire to emphasize a topic or story type, as these features tend to attract readers' attention [12].

Online news products are not as confined by space limitations, allowing organizations to experiment with both old and new prioritization cues. Researchers with the Project for Excellence in Journalism (2008) were able to determine which stories were prioritized by news organizations online based on traditional cues, including their vertical position on the page, the presence of photos, graphics, or multimedia features, and text size. Some organizations also grant somewhat equal emphasis to some topics and story types by providing a scrolling list of their top stories at the top of their homepage. Stories appearing in these windows often appear in a set chronological order and feature pictures, graphics, or both to entice the reader to click on a story the organization has deemed important.

\section{Organizational financial needs}

Although newspaper organizations have embraced online reporting, producing Web editions of their product for readers who prefer the medium, traditional newspaper organizations have beenand continue to be-built on paid subscriptions. Journalism companies are encouraged to build stable relationships with readers and employ a long-term perspective in evaluating news choices to sustain revenue [13]. Readers subscribe to the newspaper for content [14]. Research has shown non-routine newspaper readers will likely become subscribers if they notice an improvement in editorial quality and the coverage of issues, such as local, national, business, and sports stories [15]. Cyr St. C, Lacy and Guzman-Ortega [16] found circulation tends to increase when organizations spend money to improve the quality of their newspapers, incentivizing news organizations to commit to longterm goals for maintaining readership. Much of newspapers' revenue comes from print advertising, and advertisers place their messages in the product based on the promise of reaching a loyal, stable audience of subscribers [17]. Thus, the need to appeal to those readers remains key for the financial stability of newspapers.

However, the shift to online readership has transformed the business model that supports the news products. In online products, advertising rates are often based on the number of unique users or page views generated by a story [18]. In many cases, advertisers will be required to pay more money for stories that receive higher numbers of clicks [18]. Just as journalists have access to online metrics measuring user habits, so too do advertisers, who have the ability to deliver their message to a more customized audience depending on the type of story their advertisement is placed near. Therefore, news topics and story types that typically generate a large number of unique views would be more valuable for news organizations to produce for their online product.

The theory of the firm may predict differences between traditional newspaper organizations seeking both subscribers and page views and online-only organizations primarily seeking page views. The basic tenet of the theory argues that companies will give primacy to their own economic interests [2,3], and media organizations are no exception [19]. Although both newspapers and online-only organizations rely on readership figures to attract advertisers, traditional newspaper organizations have been built on establishing a steady base of subscribers while online-only organizations have needed to focus on attracting page views that can fluctuate throughout the day [14]. The theory of the firm asserts that these differing financial strategies will lead the two types of organizations to differ in how they prioritize news to suit their own economic best interests.

\section{Reader preferences}

Journalists have traditionally enjoyed a gatekeeping role, deciding what types of stories to report and how they will be presented in the news product [20]. However, the availability of online metrics allowing journalists to access information about reader preferences could potentially impacting the ways in which organizations prioritize news, putting readers in charge of determining what content should be the most visible in the publication. News organizations once relied on readership polls, leaving them only with ideas of what participants claimed to read rather than what they actually did [21]. Now, those organizations have the ability to monitor readers' habits in an instant, allowing them to prioritize items that are garnering several page views in hopes of generating even more interest and sharing.

Some online-only organizations have come to rely on reader preferences for guiding their journalistic decisions. At various AOL online Patch publications, reporters are charged with generating content that will get at least half of the town's population to click on the site [22]. At the online-only news site Gawker, journalists are pushed to write stories about scandals, crime, sex, and other topics that generate page views. Thus, readers have unprecedented opportunities to guide the prioritization of news by clicking on articles that interest them most instead of focusing on those items journalists deem most important.

Studies have shown print and online readers have different preferences for news topics and story types [23], though it is unclear whether news organizations are incorporating those preferences into their news decisions when prioritizing news. For example, crime stories and spot news tend to be frequently viewed by online readers given their immediacy, often appealing to those who access these types of stories on mobile devices [23,24]. Similarly, soft news stories on topics, such as entertainment and lifestyle, tend to be popular with readers online who like to share them with friends and family via social media $[25,26]$. Newspaper organizations have recognized the popularity of these types of stories among both print and online readers, and some have reduced their offerings of government and public affairs stories to suit reader preferences [27]. However, studies have also revealed newspaper readers tend to prefer reading more in-depth news features, exploring public affairs topics, such as governance, education, and health $[12,28,29]$, further complicating decisions regarding how news should be prioritized across print and online platforms.

Readers also tend to click on items that catch their eye, including those containing art, such as photos, videos, and graphics [12]. Newspapers that have to appeal to both print and online readers may not devote as many resources to multimedia reporting features, such as blogs and videos, as their online-only counterparts for which generating page views online is their only revenue source. However, a count of each organization's staff journalists revealed online-only organizations tend to have far fewer journalists on staff compared with traditional print organizations, potentially limiting their ability to produce multimedia features.

\section{Research questions}

This study asks what types of stories news organizations prioritize based on the platform and the organization type. Are news organizations prioritizing news differently online versus in print? Are online-only news organizations and newspaper organizations prioritizing news in ways that satisfy their own financial best interests? Ten research questions address these questions based on story topic, story type, timeliness, and reporting features. 
RQ1a: How do news organizations compare in story prominence across news topics in their print and online offerings?

RQ1b: How do newspaper and online-only publications compare in story prominence across news topics?

RQ2a: How do news organizations compare in story prominence regarding their timeliness in print and online offerings?

RQ2b: How do newspaper and online-only publications compare in story prominence regarding their timeliness?

RQ3a: How do news organizations compare in story prominence across story types in their print and online offerings?

RQ3b: How do newspaper and online-only publications compare in story prominence across story types?

RQ4a: How do the storytelling features prioritized by news organizations compare in their print and online offerings?

RQ4b: How do storytelling features prioritized by newspaper and online-only publications compare?

\section{Method}

\section{Study criteria}

This study deviated from previous research comparing international and national coverage in news publications [30] to examine those focused on providing local news. The criteria for selecting comparable organizations included a focus on generalinterest news content, rather than niche content, such as political, sports, investigative, or entertainment reports [31]. Organizations selected for this study needed to employee a minimum of three fulltime staff members dedicated to producing news rather than relying mostly on contributors and aggregated content. News organizations in this study also need to produce content at least five days a week. Print organizations selected must also charge money for print subscriptions, eliminating "shoppers" from the study.

Lists containing all newspapers in the country or world, such as Editor and Publisher's International Yearbook, are preferred for sampling [32]. However, such comprehensive lists are not available for online news sites as of yet. Also, organizations that might be considered news sites launch frequently as a result of the low financial barriers to entry online.

Two lists of online news organizations were used for this study, though neither list could be considered a population. A list of 61 online-only U.S. news organizations was obtained from the American Society of News Editors [33] from a research study conducted by the organization. The News Frontier Database [34], an online news site catalog from Columbia Journalism Review, was also used to search for news organizations. From these lists, four pairs of traditional newspaper and online-only news organizations were chosen because they were the only ones as of spring 2011 known to meet the criteria for the study. Comparable studies have used the same number of organizations or fewer $[7,30]$. Thus, the four selected pairs should provide sufficient variance to meet standards for empirical social science research.

The four pairs of organizations selected for this study were: The Bay Citizen and San Francisco Chronicle; Seattlepi and The Seattle Times; TucsonSentinel and Arizona Daily Star; and New Haven Independent and New Haven Register.

\section{Item collection}

A constructed week was used as a strategy to reduce standard error in the analysis of articles [35]. Some of the organizations in the study limit their publishing to five or six days a week. Therefore, one constructed week, totaling five collection days, was used for data collection to reduce the effect of possible content anomalies on any given collection day on the total data. The days selected for coding were chosen using a random-number table obtained from Stat Trek [36]. A systematic strategy for item coding was used, with each site selected at the same time each day, adjusting for varying time zones.

Three sources of data were examined: the print editions of the traditional newspaper organizations, the online editions of the traditional newspaper organizations, and the online editions of the online-only organizations. The unit of analysis was the item, which included headlines, text, pictures, graphics, and other features associated with that item. Each item was evaluated in terms of the topic or story type according to the method outlined below.

To determine how news organizations prioritize their news, the top 10 items were selected from each publication on all platforms every day using a method developed by the Pew Research Center [37]. For online stories, the prioritized items were determined based on the positioning of the article on the website, the size of its headline type and its inclusion of photos. For print stories, all articles where text begins on either the front page or the local section front pages were collected from top to bottom, with up to 10 items collected from each publication. A total of 597 items were collected for coding.

\section{Coding categories}

News items were examined for key variables, including story presentation, news topic, timeliness, and story type. Coders selected any and all items that were presented with each story from a list of six possibilities, including text story, photo/photo gallery, headshot, blog, graphics and video.

News items were then examined for the presence of one primary news topic from a list of 13: law/crime, economy/business, governance, environment/science/technology, sports, education, entertainment, safety/disasters/accidents, lifestyle, health, politics, religion and transportation. A list of topics that commonly appear in news items was compiled based on a review of four studies [5,7,30,38]. Only one topic that best describes the item was selected for each article [38].

Items were grouped into one of three categories to determine their timeliness: spot news, time peg, and evergreen. Spot news items included those that occurred unexpectedly and merited immediate coverage. Time peg items included articles published as reactions to or previews of news events, or those timed to run in relation to a calendar date. Evergreen items were counted as those without any time element that could be suitable for publication at any time.

Story type was determined by placing items into one of six categories, including hard news, news features, soft news, helpfulness articles/columns, editorials/hard news opinion columns, personal opinion and entertainment critiques/columns. Hard news stories tend to have some sense of immediacy and are often regarded as being critical for readers understanding of the news ${ }^{1}$. News features include those that involve a more in-depth look at news items ${ }^{2}$. Soft news items tend to be less urgent and often contain news regarded as less crucial for readers ${ }^{3}$. Helpfulness items, also called "news you can use," typically feature advice or a how-to approach for readers ${ }^{4}$. Editorials 
${ }^{1}$ Cheryl Gibbs and Tom Warhover, Getting the Whole Story: Reporting and Writing the News (New York: The Guilford Press, 2002), 89-90.

${ }^{2}$ Melvin Mencher, News Reporting and Writing (New York: McGraw-Hill, 2011), 178.

${ }^{3}$ Bruce Garrison, Professional News Writing (Hillsdale, CA, 1990), 27-28.

${ }^{4}$ Carole Rich, Writing and Reporting News: A Coaching Method (Boston, MA, 2010), 14.

and hard news columns include opinions on hard news, and personal opinion and entertainment critiques/columns feature opinions on soft news. Items that were posted only to promote the news organization were defined as self-promotional. Posts soliciting reader assistance in reporting the news were coded as crowdsourcing.

\section{Coding}

A 7 page codebook was developed to provide standard measures and instructions for this study. Two coders, including the researcher and an undergraduate journalism student, were trained for approximately 35 hours prior to the start of the coding process. Following training, an intercoder reliability test was conducted prior to the start of coding on 100 items, approximately 17 percent of the sample. Coding agreement ranged from 100 percent for story presentation to 84 percent for story type. The overall level of agreement across all variables was 90 percent. In a mid-study check on intercoder reliability, overall level of agreement across all variables was 91 percent.

\section{Findings}

\section{Story types}

In spite of reader preferences that would dictate differences in the items prioritized by traditional newspaper and online-only news organizations, prominent stories selected by those publications were similar in print and online with a few notable exceptions. Both newspaper and online-only organizations prioritized hard news content the most across platforms, each devoting about $45 \%$ of the top spots to the story type (Table 1). The data revealed organizations differ regarding the prioritization of news features in both print and online. There were more news feature items in the top 10 items in online-only publications (33.30\%) than newspapers $(25.40 \%), \chi^{2}(1, n=597)=4.23$, $\mathrm{p}<0.05$. However, there were significantly more news feature items in the top 10 items in print $(37.80 \%)$ than online $(24.00 \%), \chi^{2}(1$, $\mathrm{n}=597)=11.84, \mathrm{p}<0.001$.

Differences were also revealed among print and online platforms regarding soft news and helpful news items. More soft news items were prioritized online $(24.50 \%)$ than in print $(12.20 \%), \chi^{2}(1, n=597)=11.44$, $\mathrm{p}<0.001$. More helpfulness items were also prioritized online $(2.90 \%)$

\begin{tabular}{|l|c|c|c|c|}
\hline & Online-only & $\begin{array}{c}\text { Newspaper } \\
\text { (Print) }\end{array}$ & $\begin{array}{c}\text { Newspaper } \\
\text { (Online) }\end{array}$ & Total \\
\hline Hard News & 89 & 83 & 94 & 266 \\
\hline News Feature & $43.0 \%$ & $46.1 \%$ & $44.8 \%$ & $44.6 \%$ \\
\hline Soft News & 69 & 68 & 31 & 168 \\
& $33.3 \%$ & $37.8 \%$ & $14.8 \%$ & $28.1 \%$ \\
\hline Helpfulness & $18.4 \%$ & $12.2 \%$ & $30.5 \%$ & $20.8 \%$ \\
\hline Editorials & 2 & 0 & 10 & 12 \\
& $1.0 \%$ & $0.0 \%$ & $4.8 \%$ & $2.0 \%$ \\
\hline Opinion Columns & 4 & 4 & 2 & 17 \\
& $1.9 \%$ & $2.2 \%$ & $0.3 \%$ & $2.8 \%$ \\
\hline
\end{tabular}

Table 1: Story type frequency by news organization platform.

\begin{tabular}{|c|c|c|c|c|}
\hline & Online-only & $\begin{array}{l}\text { Newspaper } \\
\text { (Print) }\end{array}$ & $\begin{array}{l}\text { Newspaper } \\
\text { (Online) }\end{array}$ & Total \\
\hline Law/crime & $\begin{array}{c}49 \\
23.7 \%\end{array}$ & $\begin{array}{c}41 \\
22.8 \%\end{array}$ & $\begin{array}{c}38 \\
18.1 \%\end{array}$ & $\begin{array}{c}128 \\
21.4 \%\end{array}$ \\
\hline Economy/business & $\begin{array}{c}25 \\
12.1 \%\end{array}$ & $\begin{array}{c}19 \\
10.6 \%\end{array}$ & $\begin{array}{c}28 \\
13.3 \%\end{array}$ & $\begin{array}{c}72 \\
12.1 \%\end{array}$ \\
\hline $\begin{array}{l}\text { Disaster, accident/ } \\
\text { public safety }\end{array}$ & $\begin{array}{c}10 \\
4.8 \%\end{array}$ & $\begin{array}{c}12 \\
6.7 \%\end{array}$ & $\begin{array}{c}23 \\
11.0 \%\end{array}$ & $\begin{array}{c}45 \\
7.5 \%\end{array}$ \\
\hline Politics & $\begin{array}{c}24 \\
11.6 \%\end{array}$ & $\begin{array}{c}23 \\
12.8 \%\end{array}$ & $\begin{array}{c}15 \\
7.1 \%\end{array}$ & $\begin{array}{c}62 \\
10.4 \%\end{array}$ \\
\hline Governance & $\begin{array}{c}19 \\
9.2 \%\end{array}$ & $\begin{array}{c}20 \\
11.1 \%\end{array}$ & $\begin{array}{c}11 \\
5.2 \%\end{array}$ & $\begin{array}{c}50 \\
8.4 \%\end{array}$ \\
\hline $\begin{array}{l}\text { Environment/science/ } \\
\text { technology }\end{array}$ & $\begin{array}{c}11 \\
5.3 \%\end{array}$ & $\begin{array}{c}8 \\
4.4 \%\end{array}$ & $\begin{array}{c}5 \\
2.4 \%\end{array}$ & $\begin{array}{c}24 \\
4.0 \%\end{array}$ \\
\hline Lifestyle & $\begin{array}{c}21 \\
10.1 \%\end{array}$ & $\begin{array}{c}6 \\
3.3 \%\end{array}$ & $\begin{array}{c}25 \\
11.9 \%\end{array}$ & $\begin{array}{c}52 \\
8.7 \%\end{array}$ \\
\hline Entertainment & $\begin{array}{c}9 \\
4.3 \%\end{array}$ & $\begin{array}{c}5 \\
2.8 \%\end{array}$ & $\begin{array}{c}18 \\
8.6 \%\end{array}$ & $\begin{array}{c}32 \\
5.4 \%\end{array}$ \\
\hline Education & $\begin{array}{c}6 \\
2.9 \%\end{array}$ & $\begin{array}{c}15 \\
8.3 \%\end{array}$ & $\begin{array}{c}4 \\
1.9 \%\end{array}$ & $\begin{array}{c}25 \\
4.2 \%\end{array}$ \\
\hline Health & $\begin{array}{c}14 \\
6.8 \%\end{array}$ & $\begin{array}{c}8 \\
4.4 \%\end{array}$ & $\begin{array}{c}1 \\
0.5 \%\end{array}$ & $\begin{array}{c}23 \\
3.9 \%\end{array}$ \\
\hline Sports & $\begin{array}{c}9 \\
4.3 \%\end{array}$ & $\begin{array}{c}10 \\
5.6 \%\end{array}$ & $\begin{array}{c}31 \\
14.8 \%\end{array}$ & $\begin{array}{c}50 \\
8.4 \%\end{array}$ \\
\hline Religion & $\begin{array}{c}0 \\
0.0 \%\end{array}$ & $\begin{array}{c}1 \\
0.6 \%\end{array}$ & $\begin{array}{c}0 \\
0.0 \%\end{array}$ & $\begin{array}{c}1 \\
0.20 \%\end{array}$ \\
\hline Transportation & $\begin{array}{c}10 \\
4.8 \%\end{array}$ & $\begin{array}{c}12 \\
6.7 \%\end{array}$ & $\begin{array}{c}11 \\
5.2 \%\end{array}$ & $\begin{array}{c}33 \\
5.5 \%\end{array}$ \\
\hline
\end{tabular}

Table 2: Topic frequency by news organization platform.

than in print $(0.00 \%), \chi^{2}(1, \mathrm{n}=597)=5.29, \mathrm{p}<0.05$. These differences suggest newspapers may be varying the prioritization of their online and print content regarding news features, soft news, and helpful items to suit reader preferences, though print newspapers and online-only organizations may not be distinguishing themselves from one another based on story type.

Beyond those differences revealed in story type, the items prioritized by newspapers in print and online and by online-only organizations were largely the same. The majority of items prioritized by both types of organizations were focused on local issues. Among the traditional newspapers, $70.0 \%$ of the top 10 items in print and $63.4 \%$ of those online had a local focus. In the online-only publications, $66.3 \%$ of items were also focused on local issues.

News organizations also made similar decisions regarding the timeliness of prioritized items, both in print and online. The majority of stories in both types of publications had some sort of timely focus, with about $38 \%$ of items featuring spot news and about $45 \%$ of items featuring a time peg. Only about $17 \%$ of all the prioritized items could be considered timeless. There were no significant differences regarding the timeliness of news items across publication or platform.

\section{News topics}

News topics prioritized by both newspaper and online-only organizations were also largely the same. Both types of news organizations placed an emphasis on law and crime items, with about one-fifth of the items prioritized focused on the topic in print and online (Table 2). Both newspapers and online-only organizations also emphasized other public affairs topics, including economy/business and politics items in their print and online offerings.

Significant differences were revealed in some topics, though none appeared to indicate any pattern in overall content differences among newspaper and online-only organizations on either platform. Lifestyle 
items appeared more frequently in the top 10 items online (11.00\%) than in print $(3.30 \%), \chi^{2}(1, \mathrm{n}=597)=9.37, \mathrm{p}<0.01$. Conversely, Education items appeared more frequently in print $(8.30 \%)$ than online $(2.40 \%)$, $\chi^{2}(1, \mathrm{n}=597)=11.04, \mathrm{p}<0.001$. Differences among news organizations were also revealed in two topics. There were more health items in the top 10 items in online-only publications $(6.80 \%)$ than in newspapers $(2.30 \%), \quad \chi^{2} \quad(1, \mathrm{n}=597)=7.25, \mathrm{p}<0.01$. Newspaper organizations prioritized sports items more frequently $(10.5 \%)$ than their onlineonly counterparts $(4.30 \%), \chi^{2}(1, \mathrm{n}=597)=6.70, \mathrm{p}<0.01$. Although some differences were revealed, none of these topics accounted for more than $11 \%$ of the overall news product, and no significant differences were revealed among topics that were prioritized more frequently by both types of news organizations.

\section{Storytelling features}

The storytelling features contained in items prioritized by traditional newspapers and online-only organizations both in print and online differed significantly in several ways, indicating ways in which these organizations may be distinguishing their products and offerings (Table 3). Nearly all the items in print contained a text story $(96.7 \%)$, compared with $83.2 \%$ of those items online, $\chi^{2}(1, n=597)=20.48$, $\mathrm{p}<0.001$. There were no significant differences in the frequency of text stories among newspapers and online-only organizations. Conversely, publications displayed significantly more photos and/or photo galleries in their top 10 items online (63.3\%) compared with print (45.0\%), $\chi^{2}(1$, $\mathrm{n}=597)=17.28, \mathrm{p}<0.001$.

Online-only organizations differentiated themselves from newspapers, offering significantly more storytelling features among prioritized items in three categories: photos, headshots, and graphics. Online-only organizations contained more photos and/or photo galleries in their top 10 items $(65.7 \%)$ compared to newspapers (53.6\%), $\chi^{2}(1, \mathrm{n}=597)=8.13, \mathrm{p}<0.01$. There were also more headshots in items prioritized by online-only organizations (15.9\%) compared with newspapers $(7.9 \%), \chi^{2}(1, n=597)=9.03, p<0.01$. However, the biggest difference was revealed in the frequency of graphics, with $20.8 \%$ of prioritized items in online-only organizations containing the storytelling feature compared with $4.9 \%$ in newspapers, $\chi^{2}(1$, $\mathrm{n}=597)=36.74, \mathrm{p}<0.001$.

\section{Discussion}

The types of news items prioritized by newspapers and onlineonly organizations were largely the same, both in print and online. The relative paucity of differences may reflect the relative newness of onlineonly organizations and of the online medium in general, as well as the tendency of journalists to uphold longstanding journalism routines.

\begin{tabular}{|l|c|c|c|c|}
\hline & Online-only & $\begin{array}{c}\text { Newspaper } \\
\text { (Print) }\end{array}$ & $\begin{array}{c}\text { Newspaper } \\
\text { (Online) }\end{array}$ & Total \\
\hline Text story & 176 & 174 & 171 & 521 \\
& $85.0 \%$ & $96.7 \%$ & $81.4 \%$ & $87.3 \%$ \\
\hline Photo/photo gallery & 136 & 81 & 128 & 345 \\
& $65.7 \%$ & $45.0 \%$ & $61.0 \%$ & $57.8 \%$ \\
\hline Headshot & 33 & 23 & 8 & 64 \\
& $15.9 \%$ & $12.8 \%$ & $3.8 \%$ & $10.7 \%$ \\
\hline Blog & 22 & -- & 12 & 34 \\
\hline Video & $10.6 \%$ & & $5.7 \%$ & $5.7 \%$ \\
\hline Graphics & 27 & -- & 42 & 70 \\
& $13.0 \%$ & & $20.0 \%$ & $11.7 \%$ \\
\hline
\end{tabular}

Table 3: Frequency storytelling features by news organization platform.
As journalists transition from one medium to another and from one organization to another, they tend to bring with them established ways of defining news, most of which are rooted in early newspaper foundations [39]. Many journalists have left longtime newspaper jobs in favor of fledgling online-only publications, bringing their learned methods for defining and prioritizing news with them [40]. Onlineonly journalists who share common roots with those at newspapers could partially account for the lack of differences between the two news organization types.

Another factor that may account for the lack of variety among prioritized items in newspaper and online-organizations is organizational socialization. When new employees learn about and adopt organizational values, they are said to undergo a process of organizational socialization [41]. Journalists learn routines for recognizing what news items add value to the organization-those that draw readers-and what items do not [42]. When employees transition from one news organization to another-even a different type of organization-those learned routines are not forgotten and are often incorporated into new work habits [43]. Thus, journalists at newer online-only organizations may not have adopted new routines for prioritizing news for a new audience just yet.

Conversely, many traditional newspaper organizations have mandated journalists begin recognizing and reflecting reader preferences online. In recent years, journalists have been made keenly aware of how their stories are doing online, taking note of what items receive the most page views throughout the day. Some news organizations have even gone so far as to replace reporters with $\mathrm{Web}$ producers who can monitor metrics and report stories based on the popularity of topics and story types [44]. This attention paid to reader preferences might also partially account for the lack of differences revealed in print and online, as driving page views with content appears to be practiced by both newspaper and online-only organizations to meet their financial goals.

However, some differences revealed might provide insight regarding subtle ways in which newspapers and online-only organizations distinguish themselves from one another and how news organizations vary the prioritization of their print and online offerings. The online-only news organizations selected for this study appeared to often mirror their newspaper counterparts rather than some national online publications focused on niche content that appeals to particular audiences. In doing so, the online-only organizations actually may be going against their own financial best interests by providing more indepth news content and publishing more news features online, given these types of stories typically appeal more to print readers. Newspaper organizations seem to be attempting to appeal to some of their readers' distinct print and online preferences, offering more sports, soft news and helpful items in their online editions, as well as more news features in print editions.

The primary way news organizations in the study differentiated themselves from one another and differentiated their offerings in print and online was in the use of storytelling features. Both types of organizations appear to be branching out beyond prioritizing traditional text stories online to feature more standalone storytelling items, such as photos, videos, blogs, and graphics. Yet online-only organizations seem to be leading the charge in offering more elements beyond the text story, displaying more photos/photo galleries, headshots and graphics in their top 10 news items than their newspaper counterparts. This finding is somewhat surprising given the onlineonly news organizations operate with a small fraction of the reporting 
staff compared with newspapers. It is possible journalists at those organizations have begun to adjust to the mentality of "doing more with less" that has come to be a standard in the journalism industry in recent years [45].

These findings suggest journalists may not be relinquishing their gatekeeping roles entirely in favor of reader preferences. Research has shown readers' preference for soft news that is entertaining, light, and timeless-perfect for searching online and sharing across social media platforms. Yet, both organization types continued to abide by professional norms, emphasizing hard news on local, timely items with a public affairs focus on topics such as law/crime, politics, and economy/business. Such prioritization of professional values over financial interests runs counter to the theory of the firm, which predicts organizations will act in their own financial best interests. A refusal to prioritize content that is preferred by news consumers in print and online could cost those publications readers, which in turn could lead to losses in advertising revenue, forcing news organizations to further reduce the number of journalists in already strapped newsrooms [46]. Reductions in staff often result in lower quality publications, which have been known to further repel readers [47], thus perpetuating a dangerous cycle of causing more news organizations to falter and limiting quality, diverse journalism in the United States.

Newspaper subscription rates are declining in the United States, and many news organizations have yet to discover a profitable model for advertising and distributing news online, making the need to distinguish online and print content in ways that serve each organization's own financial best interests that much more essential. Online-only organizations that rely on page views to generate advertising dollars would do well to prioritize stories that attract online readers and that prompt them to share those stories via social media, including entertainment, lifestyle, helpfulness, and spot news items. Newspapers have the added challenge of satisfying both print and online readers, and they would do well to distinguish their content based on medium. Newspaper journalists do not necessarily have to work with two distinct goals; editors could appeal to online and print readers simply by prioritizing stories for each medium that suit those reader preferences. For example, the online product might feature more of the soft news topics and spot news items as suggested above, while the print product could prioritize more public affairs topics, such as governance, education, and health, and more in-depth news features.

Although this study provides a rich set of data revealing content homogeneity among newspaper and online-organizations at the macrolevel, more could be done to explore specific content differences at the micro-level. While the items collected revealed similar story types and news topics, a closer examination regarding the ways in which those stories are told could provide some detail as to how the two organization types differ. For example, both organization types in a geographic area may present a story about a tax bill, but one organization may report the story from the perspective of the lawmakers while another could have focused on getting reactions from community members.

News editors carefully regulate their prioritization in the print product. However, online publication is not always as decisive. While some content is typically given priority on the news site based on journalists' decisions, much of it may be left to chance. The publication of online news tends to be automated throughout the day. Unless otherwise specified, whatever content is newest throughout the day may be routinely placed at the top and may simply reflect the newness of the material rather than a journalist's purposeful decision to prioritize the item.
While content analyses are suitable for providing detailed description of a phenomenon, they do nothing to explain why the phenomenon has occurred. Although it is clear from this study that news organizations have done little to distinguish themselves from one another in print or online, it is not clear why journalists in those organizations chose to prioritize the items they did. Further qualitative analysis could provide insight into the news-making process, helping guide researchers to understand and industry professionals to make decisions as journalism continues to evolve online.

\section{References}

1. Carlson N (2009) Printing the NYT costs twice as much as sending every subscriber a free Kindle. Business Insider.

2. Foss NJ, Lando H, Thomsen S (1999) The Theory of the Firm. Encyclopedia of law and economics.

3. Hoskins C, McFadyen S, Finn A (2004) Media economics: Applying economics to new and traditional media. Thousand Oaks, CA: Sage Publications.

4. Langeveld M (2009) Print is still king: Only 3 percent of newspaper reading happens online. Nieman Journalism Lab.

5. Beam RA (2003) Content differences between daily newspapers with strong and weak market orientations. Journalism \& Mass Communication Quarterly 80: $368-390$

6. Domingo D (2008) Interactivity in the daily routines of online newsrooms Dealing with an uncomfortable myth. Journal of Computer-Mediated Communication 13: 680-704

7. Schaudt S, Carpenter S (2009) The news that's fit to click: An analysis of online news values and preferences present in the most-viewed stories on azcentral. com. Southwestern Mass Communication Journal 24: 17-26.

8. Friend C Singer JB (2007) Online journalism ethics: Traditions and transitions, M.E. Sharpe.

9. Kovach B, Rosenstiel T (2001) The elements of journalism: What Newspeople Should Know and the Public Should Expect. New York: Crown Publishers.

10. Schudson M (2003) The sociology of news. New York: W.W. Norton and Company

11. Graber D (1988) Processing the news: How people tame the information tide $\left(2^{\text {nd }}\right.$ ed.) New York: Longman.

12. Tewksbury D, Althaus SL (2000) Differences in knowledge acquisition among readers of the paper and online versions of a national newspaper. Journalism \& Mass Communication Quarterly 77: 457-479.

13. Mings SM, White PB (2000) Profiting from online news: The search for viable business models. Internet publishing and beyond: The economics of digital information and intellectual property. Cambridge, MA: The MIT Press, USA.

14. Doyle S (2009) Improving newspaper subscription services. Journal of Database Marketing and Customer Strategy Management 16: 159-167.

15. Pope W (1994) Building customer loyalty: Converting casual newspaper purchaser to daily subscribers, Project for Excellence in Journalism.

16. Cyr St. C, Lacy S, Guzman-Ortega S (2005) Circulation increases follow investments in newsrooms. Newspaper Research Journal 26: 50-60.

17. Martin HJ, Souder L (2009) Interdependence in media economics: Ethical implications of the economic characteristics of news. Journal of Mass Media Ethics 24: 127-145

18. Cohn D (2008) Think you know your web traffic? Think again. The scramble for accurate online measures. Columbia Journalism Review 46: 21-22.

19. Shoemaker PJ, Reese SD (1996) Mediating the message. White Plains, NY: Longman Publishers, USA.

20. Shoemaker PJ (1996) Media gatekeeping. An Integrated Approach to Communication Theory and Research, Lawrence Erlbaum.

21. Bernt JP, Fee FE, Gifford J, Stempel III Guido H (2000) How well can editors predict reader interest in news? Newspaper Research Journal 21: 2-10.

22. Roach S (2012) The constant gardener. Columbia Journalism Review 50: 22 29. 
Citation: Cox JB (2014) News You Need to Know: Examining the Prioritization of News Content in Print and Online Publications. J Mass Communicat Journalism 4: 210. doi:10.4172/2165-7912.1000210

Page 7 of 7

23. Americans spending more time following the news (2010) Pew Research Center for the People \& the Press.

24. DeVigal A (2002) The Stanford-Poynter Eyetracking Online News Project. Poynter.

25. Curtain PA, Dougall E, Mersey RD (2008) Study compares Yahoo! News story preferences. Newspaper Research Journal 28: 22-35.

26. Thorson $E$ (2008) Changing patterns of news consumption and participation. Information, Communication \& Society 11: 473-489.

27. Beam RA (2008) Content in publicly, privately owned newspapers more alike than different. Newspaper Research Journal 29: 74-80.

28. Hollander B (2010) Local government news drives print readership. Newspaper Research Journal 31: 6-15.

29. Schönbach K, Waal E, Lauf E (2005) Online and print newspapers: Their impact on the extent of the perceived public agenda. European Journal of Communication 20: 245-258

30. Maier SR (2010) Newspapers offer more news than do major online sites. Newspaper Research Journal 3: 6-19.

31. Caplan J (2010) Have a journalism startup idea? Pitch it to Poynter. Poynter.

32. Funk M (2010) The 30-50-60 curve: Locally generated news content in small and medium-sized American dailies. Grassroots Editor 51: 12-15.

33. ASNE completes second census of online-only news sites, finds increasing diversity (2010) American Society of News Editors.

34. News Frontier Database (2010) CJR's guide to online news startups.
35. Riffe D, Aust CF, Lacy SR (1993) The effectiveness of random, consecutive day and constructed week sampling in newspaper content analysis. Journalism and Mass Communication Quarterly 70: 133-139.

36. Random number generator (2011) Stat Trek.

37. News coverage index codebook (2008) Project for Excellence in Journalism.

38. Story content analysis form (2001) Readership Institute.

39. McLuhan M (1964) Understanding Media: The Extensions of Man. New York: McGraw-Hill.

40. Tenore MJ (2011) Bay citizen embraces 4 emerging trends among news startups. Poynter.

41. Morrison EW (1993) Longitudinal study of the effects of information seeking on newcomer socialization. Journal of Applied Psychology 78: 173-183.

42. Breed W (1955) Social control in the newsroom: A functional analysis. Socia Forces 33: 326-335.

43. Ferrante $\mathrm{J}$ (2011) Sociology: A global perspective ( $7^{\text {th }}$ ed.) Cengage Learning.

44. Farhi P (2010) Traffic problems. American Journalism Review, 32: 46-51.

45. Myers S (2012) Numbers show that newspapers are indeed doing more with less. Poynter.

46. Irvine D (2012) Newspaper ad revenues are falling over a cliff. Accuracy in Media.

47. Haughney C (2012) Newspapers Cut Days from Publishing Week. The New York Times. 